\title{
Reduced pathogenicity of velogenic NDV strain AF22420-I via site-directed mutagenesis of $\mathrm{V}$ gene
}

\author{
Bei Ru Lee ${ }^{\mathrm{a}, \mathrm{b}}$, Jeevanathan Kalyanasunandramc ${ }^{\mathrm{c}}$ Kavitha Murulitharan ${ }^{\mathrm{a}}$, Kok Song Lai ${ }^{\mathrm{d}}$, Suet Lin Chia ${ }^{\mathrm{a}, \mathrm{b}^{*}}$, \\ Khatijah Yusoffa, b* $^{*}$ \\ aDepartment of Microbiology, Faculty of Biotechnology and Biomolecular Sciences, Universiti Putra Malaysia, 43400 UPM Serdang, \\ Selangor, Malaysia \\ ${ }^{b} U P M-M A K N A$ Cancer Research Laboratory, Institute of Bioscience, Universiti Putra Malaysia, 43400 UPM Serdang, Selangor, \\ Malaysia \\ 'Virology Unit, Infectious Disease Research Center (IDRC), Institute for Medical Research (IMR), National Institute of Health (NIH), \\ No. 1, Jalan Setia Murni, U13/52, Seksyen U13 Setia Alam, 40170 Shah Alam, Selangor, Malaysia \\ ${ }^{d H e a l t h ~ S c i e n c e ~ D i v i s i o n, ~ A b u ~ D h a b i ~ W o m e n ' s ~ C o l l e g e, ~ H i g h e r ~ C o l l e g e s ~ o f ~ T e c h n o l o g y, ~} 41012$ Abu Dhabi, United Arab Emirates
}

Received 15th March 2021 / Accepted 4th July 2021

\begin{abstract}
Newcastle disease virus (NDV), an avian paramyxovirus, has the potential to be used as an anticancer therapeutic vaccine due to its oncolytic and immunostimulatory activities. The virus can be categorised into three pathotypes: lentogenic, mesogenic, and velogenic; of the three pathotypes, the lentogenic strains such as the La Sota are the preferred pathotype for vaccine development due to their low virulence to birds. On the other hand, the translation of the virus to clinic of the velogenic strain AF2240-I is hindered by its virulence towards birds although it exhibits strong oncolysis with significant outcomes both in vitro and in vivo. This study aims to reduce the pathogenicity of AF2240-I yet retaining the anti-cancer properties of the virus. To achieve this, the $\mathrm{V}$ protein that acts as an interferon antagonist was chosen to be mutated. It is a non-structural protein that does not interfere with the binding and infection of the virus; hence, mutation of this virulence factor was deducted to be able to reduce harm to the avian species but retain its anti-cancer properties as much as possible. The $\mathrm{V}$ protein, which was produced from the insertion of an additional $G$ into a conserved editing site of the $P$ gene, was mutated by substituting the $G$ nucleotide at position 411 from the start of $P$ gene to a T nucleotide. This mutation will produce a premature stop codon from the $\mathrm{V}$ mRNA, resulting in a truncated $\mathrm{V}$ protein; but only causes a silent mutation in the $\mathrm{P}$ protein. The recombinant virus was recovered by the use of BHK cells stably expressing the phage T7 RNA polymerase. The pathogenicity of the mutated virus was determined in 9to 11-day-old embryonated SPF chicken eggs. The mean death time (MDT) was determined to be 73.6 hours at the minimal lethal dose of $10^{-7}$, resembling to that of a mesogenic strain. The virulence of the mutated virus has been successfully reduced where it could be potentially used as the vector for the development of recombinant oncolytic virus for cancer treatment.
\end{abstract}

Keywords: Newcastle disease virus, oncolytic virus, reduced virulence

\section{INTRODUCTION}

The Newcastle disease virus (NDV) is a pleomorphic RNA virus with diameters ranging from 100 to $500 \mathrm{~nm}$. Its single-stranded negative sense RNA genome of either 15198, 15192 or 15186 nt (Czeglédi et al., 2006) encodes for the nucleocapsid protein (NP), phosphoprotein (P),

\footnotetext{
*Author for correspondence: Suet Lin Chia, Khatijah Yusoff, Department of Microbiology, Faculty of Biotechnology and Biomolecular Sciences, Universiti Putra Malaysia, 43400 UPM Serdang, Selangor, Malaysia. Email suetlin@upm.edu.my; kyusoff@upm.edu.my
} 
matrix protein (M), fusion protein $(\mathrm{F})$, haemagglutinin-neuraminidase $(\mathrm{HN})$, and large polymerase protein (L) (Figure 1a). These genes are flanked at the 3' and 5'-ends with a $55 \mathrm{nt}$ leader and $114 \mathrm{nt}$ trailer terminal sequences which are untranslated regions (UTRs) involved in the transcription, replication, and packaging of genomic and antigenomic RNAs (Yusoff \& Tan, 2001; Yan \& Samal, 2008). Each gene contains a gene start and a gene end sequences; and intergenic sequences of 1 to 47 nucleotides are located in between each gene (Figure 1a) (Yusoff et al., 1987; Galinski, 1991; Lamb \& Kolakofsky, 1996; Krishnamurthy \& Samal, 1998). The virus has a lipid bilayer coat derived from the host cell membrane, where the two surface glycoproteins, the $\mathrm{HN}$ and F proteins, are embedded within. The $\mathrm{M}$ protein forms a layer beneath the lipid membrane, whereas the NP, $\mathrm{P}$ and $\mathrm{L}$ proteins are associated with the RNA genome to form the ribonucleoprotein (RNP) complex (Figure 1b; Yusoff \& Tan, 2001). Two non-structural proteins, $\mathrm{V}$ and $\mathrm{W}$ proteins, are produced by RNA editing of the $P$ gene during transcription whereby one or two non-templated $G$ nucleotides are inserted at the conserved position 484 in the sequence 476-5'-UAAAAAGGGCCCA-3'-489 ( Steward et al., 1993; Mebatsion et al., 2001). Three distinct populations of messenger RNAs (mRNAs) are generated in a ratio of approximately $7: 3: 1$; the $P$ protein is encoded by an unedited $\mathrm{P}$ open reading frame (ORF); $\mathrm{V}$ protein is encoded by V ORF with +1 frameshift; and $\mathrm{W}$ protein is encoded by $\mathrm{W}$ ORF with +2 frameshifts ( Steward et al., 1993; Mebatsion et al., 2001).

(a)

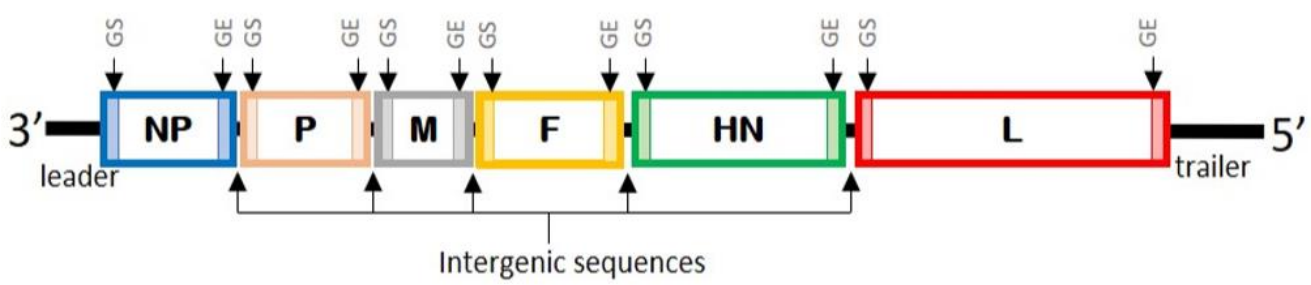

(b)

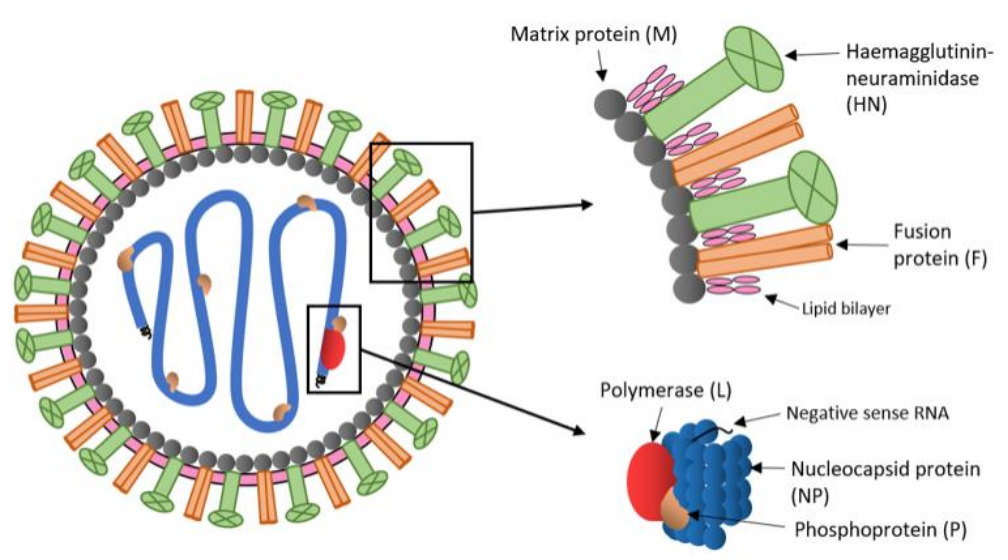

Figure 1. (a) NDV genome organisation. The NDV RNA is negative-sensed, as depicted by the 3' to 5' arrangement. The genes are arranged in the order of 3'-NP-P-M-F-HN-L-5'. It is flanked by a leader sequence of $55 \mathrm{nt}$ leader sequence and a $114 \mathrm{nt}$ trailer sequence, and contains intergenic sequences in between each gene, all which are untranslated regions (UTRs). Each gene has its own gene start (GS) and gene end (GE) at the beginning and end, flanking the coding sequences. (b) Schematic diagram of an NDV. The virus is enveloped by a lipid bilayer with the surface proteins $\mathrm{F}$ and $\mathrm{HN}$ embedded in it. The $\mathrm{M}$ proteins lie just below the lipid bilayer. The NP encapsidates the negative sense RNA and associated with $\mathrm{P}$ and $\mathrm{L}$ to form the ribonucleoprotein (RNP) complex. (Adapted from Morodomi et al., 2013). 
NDV strains are categorised into three pathotypes: lentogenic, mesogenic, and velogenic, depending on the severity in disease they cause in birds, with the velogenic strains causing high mortality in the birds, resulting in severe loss in the poultry industry (Lancaster, 1976). The pathotypes can be determined by three well established methods: intracerebral pathogenicity index (ICPI), intravenous pathogenicity index (IVPI), and mean death time (MDT). Lentogenic NDV does not cause overt pathology in adult birds, has low virulence, is non-lytic, and only causes mild or subclinical respiratory infection; mesogenic NDV causes respiratory disease with occasional nervous signs, but with low mortality; whereas velogenic strains are lytic (cytotoxic) and causes high mortality, and are further divided into two forms: viscerotropic, with the symptom of haemorrhagic lesions of digestive tract; and neurotropic, which causes respiratory and neurological symptoms (Alexander, 1988). Extensive studies have been done to identify the virulence factor of NDV, and it has been found that the virus pathogenicity are influenced by many factors: the $\mathrm{F}$ and $\mathrm{HN}$ proteins are involved in the infectivity of the virus; the $\mathrm{V}$ protein acts as an interferon (IFN) antagonist; and other factors such as the length of intergenic sequences and the $\mathrm{L}$ protein that affect the level of virus replication (Reichard et al., 1992; Sergel et al., 1993a; Sergel et al., 1993b; Deng et al., 1997; Sergel et al., 2000; Mebatsion et al., 2001; Morrison, 2003; Huang et al., 2004; de Leeuw et al., 2005; Rout \& Samal, 2008; Yan \& Samal, 2008; Khattar et al., 2009; Qiu et al., 2016; Yu et al., 2017a; Yu et al., 2017b; Yan et al., 2020)

NDV has been reported to show oncolytic effects since the mid-1950s (Flanagan et al., 1955). It has since been repeatedly studied for its antitumour properties both in vitro and in vivo. In addition, several NDV strains have been studied in clinical trials phase I and II, and the outcomes were promising (Lam et al., 2011; Song et al., 2019). In view of this, many laboratories worldwide have investigated the local NDV strains for their oncolytic properties (Schirrmacher, 2016). The Malaysian strain AF2240-I is a velogenic strain with ICPI of 1.9 and MDT of $48 \mathrm{~h}$ (Lai \& Ibrahim, 1987; Lee et al., 2006; Murulitharan et al., 2013). This virus is able to kill the cancer cells with high efficiency and specificity (Kalyanasundram et al.,
2018). However, due to its velogenic characteristic, it would be hard for it to enter further clinical research either as an anti-tumour agent or as a vaccine vector. This study aims to mutate the strain to reduce its virulence, so that its potential as an anti-tumour agent can be explored with less harm to the avian species. Although the $\mathrm{F}$ protein was deemed the key virulence factor and mutation at the $F$ cleavage site (FCS) significantly changed the pathotype of NDV (Peeters et al., 1999), it was found that the FCS also plays an important role in the oncolytic ability of NDV. The study by Zamarin et al. (2009) showed that recombinant virus with enhanced fusogenicity by introduction of a polybasic protease cleavage site enhanced virus spread among tumour cells, resulting in increased viral replication and enhanced oncolytic ability in tumour cell lines. Moreover, the study by Cheng et al. (2016) showed that the replacement of a mesogenic FCS with a lentogenic one resulted in poor growth in cell culture, posing development issues for the virus as oncolytic agents. Hence, among all the virulence factors that was thus far discovered, the $\mathrm{V}$ protein was chosen to be mutated because it is not a surface protein and would not affect binding and infection of the virus. In instances where a virus is to be used as anti-tumour agent or vaccine vector, it would be optimal if the infectivity of the virus is retained.

\section{MATERIALS AND METHODS}

\section{Animal ethics}

This study was carried out in strict accordance with the recommendations in the Guide for the Care and Use of Laboratory Animals. Specificpathogen-free (SPF) embryonated chicken eggs were obtained from Malaysian Vaccines and Pharmaceuticals Sdn. Bhd. (MVP). The protocols were approved by the Institutional Animal Care and Use Committee (IACUC) of Universiti Putra Malaysia (UPM/IACUC/AUP-R074/2017).

\section{Plasmids, viruses and cells}

The plasmid pOLTV5(rAF-GFP), which comprises cDNA of AF2240-I in pOLTV5 transcription vector with green fluorescent protein (GFP) inserted between the $\mathrm{M}$ and $\mathrm{F}$ 
intergene, was obtained from the Virology Laboratory, Faculty of Biotechnology \& Biomolecular Sciences. The pOLTV5 vector, which is a kind gift from Dr. Ben Peeters, Wageningen University (Peeters et al., 1999), is a low copy number vector which is suitable for replication of large inserts as it minimises stress to the cells; whereas GFP is used as a marker for gene expression. Three helper plasmids used in this study: pCIneo- NP, pCIneo-P, and pCIneo-L were obtained from Virology Laboratory, Faculty of Biotechnology and Biomolecular Sciences, UPM.

All viruses were propagated in 9-day-old embryonated chicken eggs, and were chilled at $4.0^{\circ} \mathrm{C}$ overnight before the allantoic fluid were harvested.

BHK cells stably expressing the phage T7 RNA polymerase (BSRT7/5) was obtained as a gift from Prof. Dr. Karl-Klaus Conzelmann, Ludwig-Maximilians-University Munich, Germany (Buchholz et al., 1999). The cells were grown and maintained in Glasgow's minimum essential medium (GMEM) (Himedia Laboratories, India) containing 1\% tryptosephosphate broth (Sigma-Aldrich, USA), $1 \times$ MEM amino acid (Himedia Laboratories, India), and 5\% new-born calf serum (Himedia Laboratories, India), and selected in $1 \mathrm{mg} / \mathrm{mL} \mathrm{G} 418$ antibiotic. The cells were grown in $5 \% \mathrm{CO} 2$ incubator (Memmert, Germany).

\section{Introduction of mutation into $P$ gene}

A single mutation of $G$ at position 411 from the start of $P$ gene into $T$ (location on plasmid map as shown in Figure 2a) was introduced into pOLTV5(rAF-GFP) via site- directed mutagenesis. This mutation will result in a premature stop codon when the $\mathrm{V}$ mRNA was transcribed, hence producing a truncated $\mathrm{V}$ protein (as shown in Figure 2b). The mutated plasmid was denoted as pOLTV5(rAF-411G $>$ TGFP).

PCR using the primers $411 \mathrm{G}>\mathrm{T}-\mathrm{F}$ and 411G $>$ T-R (Table 1) was performed to introduce the $411 \mathrm{G}>\mathrm{T}$ mutation. Another PCR fragment covering the region starting from BsiWI to PspOMI was produced using the primers BsiWI-F and PspOMI-R (Table 1). The two PCR fragments were ligated using T4 DNA ligase to form the insert, denoted as BsiWI-411G $>$ T-PacI, which is about $2.8 \mathrm{~kb}$. The vector of about $17.8 \mathrm{~kb}$ in size was also obtained by PCR using the primers NDV-PacI-F and NDV-BsiWI-R (Table 1). After PCR, the fragment was digested with $D p n \mathrm{I}$ to remove all plasmid template and then gel purified using Wizard $\AA$ SV Gel and PCR Clean-up System (Promega, USA). Both the vector and insert were double- digested with BsiWI-HF® and PacI and purified using Wizard ${ }^{\circledR}$ SV Gel and PCR Cleanup System (Promega, USA). They were then ligated with T4 DNA ligase to form a plasmid of 18, 392 bp and transformed into NEB ${ }^{\circledR}$ 10-beta E. coli (New England Biolabs, UK) for amplification. Plasmids were extracted from a few colonies and intergenic PCR was carried out using primers that flanked the intergenic regions NP-P, P-M, M-F, F-HN, and HN-L to check the integrity of the DNA. Plasmids that have correct bands were sent for full-length sequencing.

\section{Recovery of recombinant viruses}

BSRT7 $/ 5$ cells were grown to $80 \%$ confluency in 6 -well plates. The full-length pOLTV5(rAF411G $>$ T-GFP) plasmid was co-transfected with the three helper plasmids pCIneo-NP, pCIneo-P, and pCIneo-L in an optimised ratio of 1: 0.4: 0.2: 0.2 (Nakaya et al., 2001) into the BSRT7/5 cells using Lipofectamine ${ }^{\mathrm{TM}} 3000$ reagent (Thermo Fisher Scientific, USA) according to manufacturer's instructions. The 6-well plates were observed under fluorescence microscope at $96 \mathrm{~h}$ post transfection. Supernatants and cell monolayers were harvested 4 days after transfection, cleared by centrifugation, and were inoculated into embryonated chicken eggs for propagation of virus.

\section{Virus propagation in embryonated chicken eggs}

NDV was propagated in the allantoic cavity of 9to 11-day old embryonated chicken eggs. An aliquot of $100 \mu \mathrm{L}$ of the virus was inoculated into the lateral area of the allantoic cavity using a $1 \mathrm{~mL}$ syringe though the hole punched into the shell above the air sac, which was sealed with wax after inoculation. The inoculated eggs were incubated at $37^{\circ} \mathrm{C}$ for $48-96 \mathrm{~h}$. At the end of the incubation, the eggs were chilled in $4^{\circ} \mathrm{C}$ for a minimum of 4 h. Then the allantoic fluid was harvested by breaking the eggshell above the airspace. The allantoic fluid collected was clarified by 
centrifugation at $8,000 \mathrm{rpm}(\sim 8,800 \times g)$ at $4^{\circ} \mathrm{C}$ for 20 min. Haemagglutination (HA) test was performed prior to storing at $-80^{\circ} \mathrm{C}$. The virus was passaged three more times in embryonated chicken eggs before subjected to mean death time analysis.

\section{Viral RNA isolation, RT-PCR, and sequence analysis}

Genomic RNA was extracted using the TRIzol method. cDNA was synthesised using RevertAid First Strand cDNA synthesis kit (Thermo Fisher Scientific, USA) and a region covering the site of mutation on the $P$ gene was amplified using Q5 High Fidelity DNA polymerase from New England Biolabs (New England Biolabs, UK). PCR products were sent for sequencing for verification of the mutation.

\section{Determination of mean death time}

Mean death time (MDT) of the recombinant NDV was determined using the method as described by OIE (2012) with slight modification.
The allantoic fluid with the virus isolate was harvested, centrifuged for $2000 \times g$ for $5 \mathrm{~min}$, and filtered using $0.22 \mu \mathrm{m}$ filter. A series of 10 -fold dilutions of the allantoic fluid was prepared. Each dilution $(0.1 \mathrm{~mL})$ of $10^{-2}$ to $10^{-9}$ were injected into the allantoic cavity of five 9-days old specificpathogen-free (SPF) chicken eggs in the morning. The virus dilutions were kept in chiller and injected into five more chicken eggs 8 hours later, in the evening. All eggs were incubated at $37^{\circ} \mathrm{C}$ for 7 days and observed twice (morning and evening) daily for embryo death. The viability of the embryos was determined by candling. Under the candling lamp, healthy embryos have clear, well-defined blood vessels and will move in response to the light; whereas dead embryos are indicated by deteriorating or disrupted blood vessels (Ernst et al., 2004). The lowest dilution which killed all the embryos was determined to be the minimum lethal dose, and the average death time of the minimum lethal dose was calculated and reported as the MDT.

Table 1. List of primers used in this study.

\begin{tabular}{lll}
\hline Primers & Primer sequence & Primer name \\
\hline $1^{\text {a }}$ & 5'-ATATGGGCCCATGGTCtAGTCCCCAGGAAGGATTC-3' & 411G>T-F \\
\hline $2^{\text {a }}$ & 5'-GCGCTTAATTAACTCGGAAGGGTGTTGTACTG-3' & 411G>T-R \\
\hline $3^{\text {b }}$ & 5'-GCATCGTACGGGTAGAAGGTGTGAACATCGAGTG-3' & BsiWI-F \\
\hline $4^{\text {b }}$ & 5'-GCGCGGGCCCTT'TTAGCATTAGATGGTTTATTGCTCAG & PspOMI-R \\
& CTT GTCG-3' & \\
\hline $5^{\text {c }}$ & 5'-GCGCTTAATTAAATCTGCCACAGCGGGCGGACCTGATAT & NDV-PacI-F \\
& GGG-3' & \\
\hline $6^{\text {c }}$ & 5'-TTCACACCTTCTACCCGTACGAT-3' & NDV-BsiWI-R
\end{tabular}

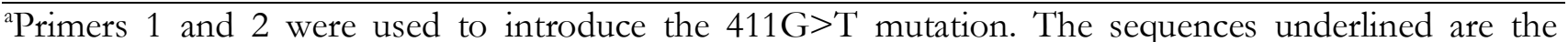
restriction enzymes PspOMI and PacI respectively, and the nucleotide ' $t$ ' in lowercase font indicates the mutation which is $\mathrm{G}>\mathrm{T}$.

${ }^{b}$ Primers 3 and 4 were used to amplify a PCR fragment covering the region starting from Bsi WI to PspOMI. The sequences underlined are the restriction enzymes Bsi WI and PspOMI respectively.

'Primers 5 and 6 were used to amplify the NDV vector. The sequences underlined are the restriction enzymes PacI and BsiWI respectively. 
(a)

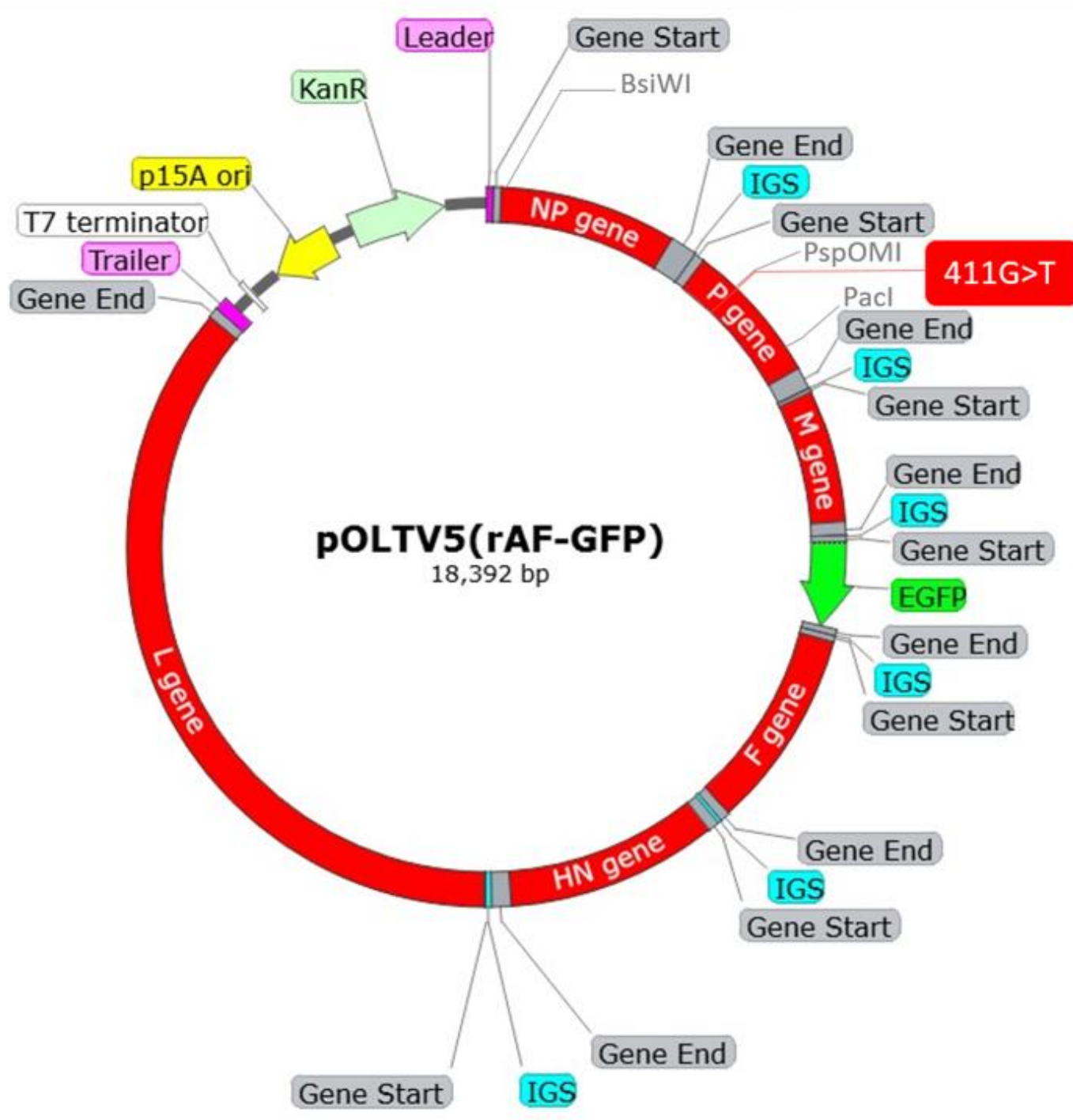

(b)

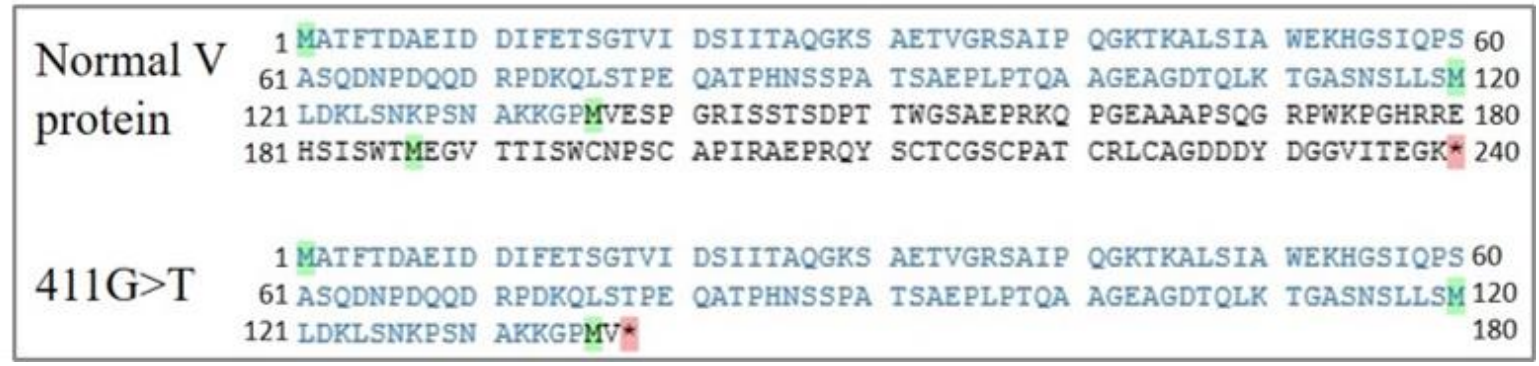

Figure 2. (a) Plasmid map of pOLTV5(rAF-GFP) showing the mutation 411G $>T$. The mutation is a single nucleotide change from $G$ to $T$ at position 411 from the start of $P$ gene. (b) A comparison of amino acid sequences of a normal $\mathrm{V}$ protein and one with $411 \mathrm{G}>\mathrm{T}$ mutation. The mutation will produce a premature stop codon, hence producing a truncated $\mathrm{V}$ protein. 


\section{RESULTS}

\section{Construction and verification of mutated $411 G>T N D V$ plasmid}

In order to introduce a premature stop codon into the $\mathrm{V}$ protein, a primer containing the desired mutation $411 \mathrm{G}>\mathrm{T}$ was used to perform sitedirected mutagenesis on the pOLTV5(rAF-GFP) plasmid, as described above. The ligation mixture of desired insert with mutation and vector was transformed into E. coli for selection and amplification. Plasmids were extracted from three purified colonies denoted as pOLTV5(rAF411G $>$ T- GFP)-2, -4 , and -7 respectively. They were subjected to intergenic PCR to check the plasmid integrity, and expected DNA fragment sizes were observed for all plasmids (Figure 3). Plasmids pOLTV5(rAF-411G $>$ T-GFP) -4 and -7 were selected for sequencing, and the sequencing results showed the successful incorporation of mutation of $\mathrm{G}$ into $\mathrm{T}$ at the desired site (Figure 4). Chromatogram of the sequencing showed clear, single peak. The results above showed the successful cloning of the $411 \mathrm{G}>\mathrm{T}$ mutation into pOLTV5(rAF-GFP). These plasmids were then transfected for recovery of virus particles.

\section{Recovery, verification, and propagation of recombinant virus $r A F-411 G>T-G F P$}

Infectious NDV with mutated $\mathrm{V}$ protein were generated by transfection. Transfection supernatant was harvested on $96 \mathrm{~h}$ posttransfection and inoculated into 9-days-old SPF embryonated chicken eggs for propagation (Passage 1). Allantoic fluid was harvested $72 \mathrm{~h}$ post-inoculation and was subjected to HA test. HA of Passage 1 showed no HA titre for rAF$411 \mathrm{G}>\mathrm{T}-\mathrm{GFP}-4$ and a low titre of $2^{1} \mathrm{HA}$ units for rAF-411G $>$ T-GFP-7 (Figure 5a). RNA was isolated for rAF-411G>T-GFP-7 and after construction of cDNA, subsequent PCR amplified DNA was sent for sequencing. However, the sequencing result did not show the desired mutation of $\mathrm{G}$ into $\mathrm{T}$, but into $\mathrm{C}$ instead $(411 \mathrm{G}>\mathrm{C})$, as shown in Figure 5b. An additional mutation of $\mathrm{T}$ into $\mathrm{C}$ further downstream, at position 427 from start of $P$ gene coding sequence, was also observed $(427 \mathrm{~T}>\mathrm{C})$. The changes in amino acids in both $\mathrm{P}$ and $\mathrm{V}$ proteins caused by these mutations were as listed in Table 2.

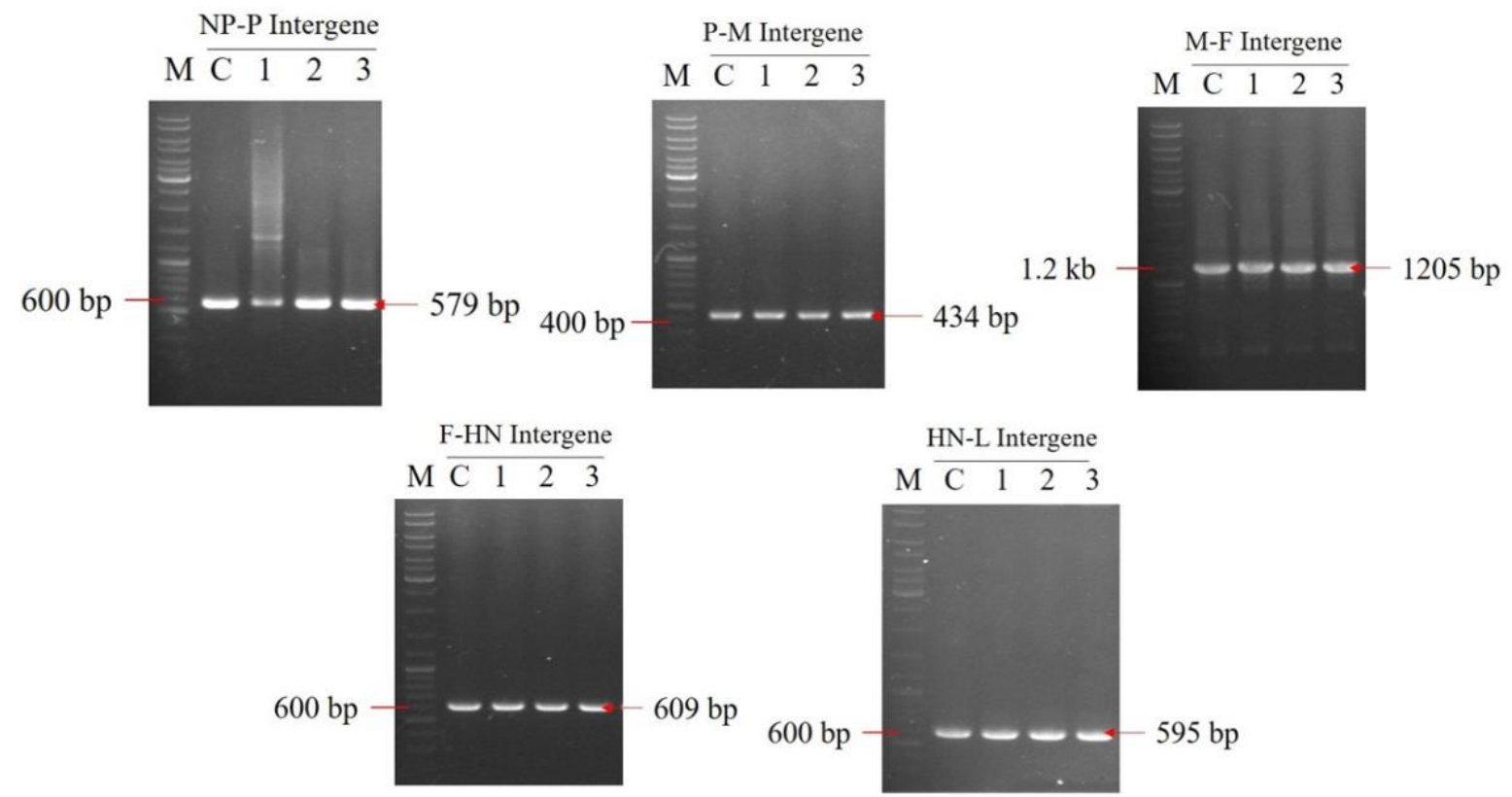

Figure 3. Agarose gel electrophoresis of intergenic PCR of purified pOLTV5(rAF- 411G>T-GFP). Correct band sizes were observed for NP-P intergene region at $579 \mathrm{bp}$; P- M intergene region at 434 bp; M-F intergene at $1205 \mathrm{bp}$; F-HN region at $609 \mathrm{bp}$; and HN- L intergene at $595 \mathrm{bp}$. Lane M: GeneRuler ${ }^{\mathrm{TM}}$ DNA Ladder Mix (Thermo Fisher Scientific, USA); Lane C: Positive control which is pOLTV5(rAFGFP); Lane 1: pOLTV5(rAF-411G>T-GFP)-2; Lane 2: pOLTV5(rAF-411G>T-GFP)-4; Lane 3: pOLTV5(rAF-411G>T-GFP)-7. 
(A)

Conserved editing site

Sequence of pOLTV5(rAF-

GFP)

Sequencing of pOLTV5(rAF-

$411 \mathrm{G}>\mathrm{T}$-GFP) from colony 4

Sequencing of pOLTV5(rAF$411 \mathrm{G}>\mathrm{T}-\mathrm{GFP})$ from colony 7

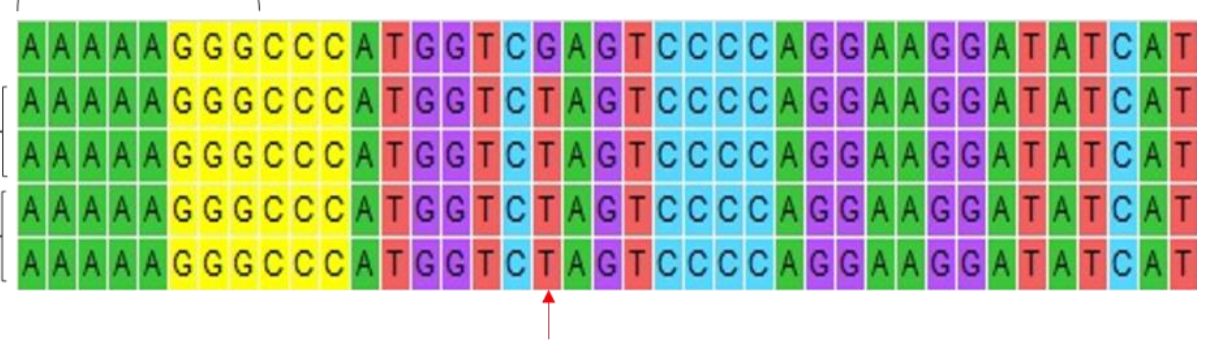

Point of mutation

(B)

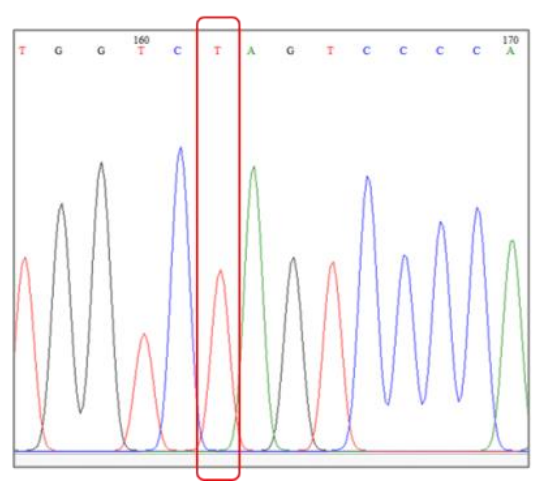

(C)

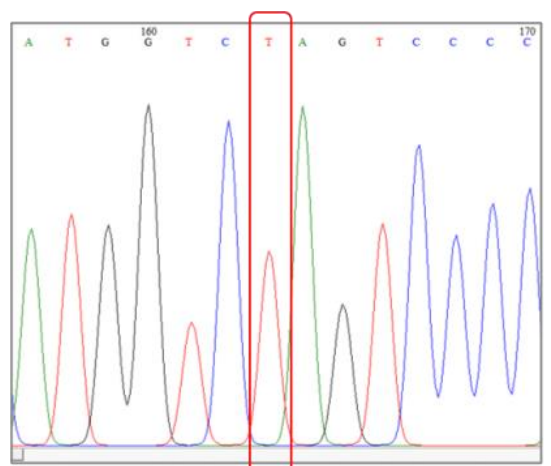

Figure 4. Sequencing results of plasmids purified with transformants of pOLTV5(rAF-411G>T-GFP). The desired mutation $411 \mathrm{G}>\mathrm{T}$ was observed from the alignment of sequencing results (A). The chromatograms of (B) pOLTV5(rAF-411G>T- GFP)-4 (B) pOLTV5(rAF-411G>T-GFP)-7 showed clear single peaks.

(a)

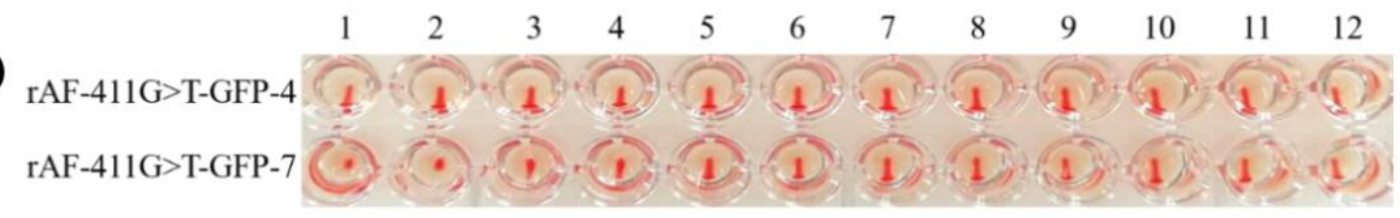

(b) Sequence of pOLTV5(rAF-GFP) AAAAAGGGCCCATGGTCGAGTCCCCAGGAAGGATATCATCAACC Sequencing with primer \#22 AAAAAGGGCCCATGGTCCAGTCCCCAGGAAGGACATCATCAACC Sequencing with primer \#23 AAAAAGGGCCCATGGTCCAGTCCCCAGGAAGGACATCATCAACC Sequencing with primer \#24 AAAAAGGGCCCATGGTCCAGTCCCCAGGAAGGACATCATCAACC

Point of mutation $411 \mathrm{G}>\mathrm{C}$
Additional mutation $427 \mathrm{~T}>\mathrm{C}$

Figure 5. Verification of Passage 1 allantoic fluid inoculated with rAF-411G>T-GFP- 4 and -7. (a) HA test showed that no HA was observed for rAF-411G>T-GFP-4; whereas a HA titre of $2^{1}$ was observed for $\mathrm{rAF}-411 \mathrm{G}>\mathrm{T}-\mathrm{GFP}-7$. (b) The sequencing results showed that the desired mutation of $411 \mathrm{G}>\mathrm{T}$ was not observed, instead, the $T$ nucleotide has changed into $C$. There is also an additional mutation of $T$ into $C$ at position 427 from the start of $P$ gene.

Table 2. Changes in $\mathrm{P}$ and $\mathrm{V}$ protein caused by the mutations $411 \mathrm{G}>\mathrm{C}$ and $427 \mathrm{~T}>\mathrm{C}$.

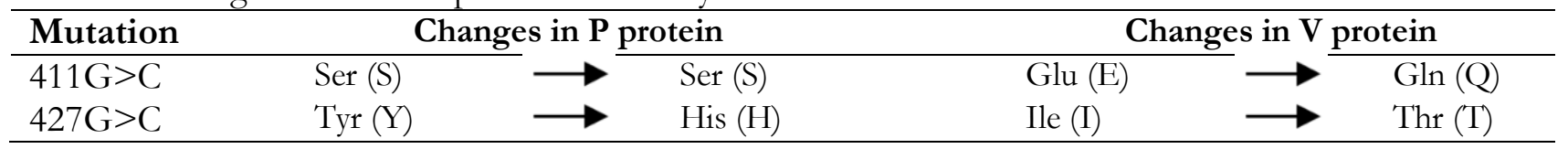


Both rAF-411G $>$ T-GFP-4 and -7 were subjected for further passaging (blind passaging in the case of rAF-411G>T-GFP-4). The allantoic fluid harvested from Passage 2 still showed no titre for rAF-411G $>$ T-GFP-4, but a higher titre of $2^{6}-2^{7}$ now for rAF- $411 \mathrm{G}>\mathrm{T}-\mathrm{GFP}-7$ (Figure 6a).

Only rAF-411G > T-GFP-7 was subjected to next passaging, and harvested allantoic fluid showed a consistent virus titre of $2^{6}$ (Figure 6b). RNA isolation was performed again for Passage 3 rAF-411G>T-GFP-7 and after cDNA construction, the PCR amplified DNA was sent for sequencing. Sequencing result of Passage 3 still showed the mutations $411 \mathrm{G}>\mathrm{C}$ and $427 \mathrm{~T}>\mathrm{C}$ (Figure 6c). Regardless, the effect of these mutations on the pathogenicity of the recombinant virus should be determined, hence it was proceeded with the testing of pathogenicity.

\section{Determination of pathogenicity}

The mutated virus rAF-411G>T-GFP-7 was subjected to MDT assay using 9-days-old SPF embryonated chicken eggs. MDT results obtained showed that the minimum lethal dose that kill all inoculated embryonated chicken eggs was at dilution $10^{-7}$, and the mean death time calculated from this dose was $73.6 \mathrm{~h}$, placing this recombinant NDV at the mesogenic range.

$$
M D T=\frac{72(4)+96+64(3)+72+88}{10}=\frac{736}{10}=73.6 h
$$

(a)

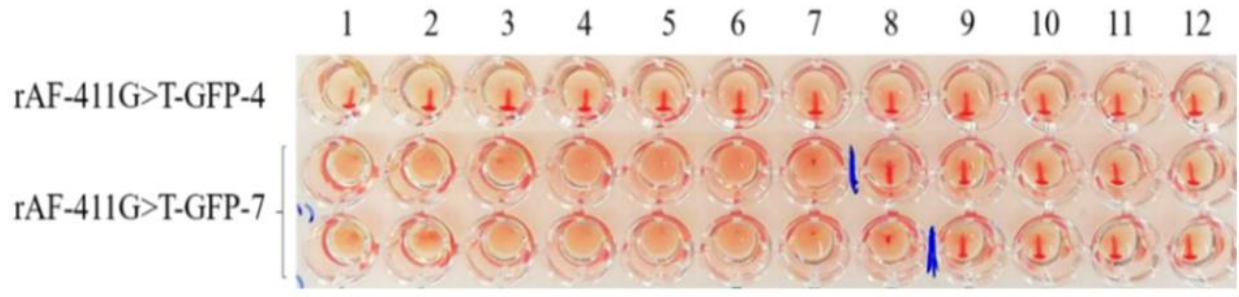

(b)

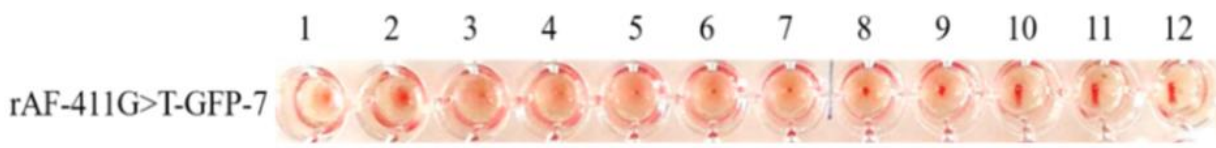

(c) Sequence of pOLTV5(rAF-GFP) AAAGGGCCCATGGTCGAGICCCCAGGAAGGATATCATCAACC Sequencing with primer \#22 AAAGGGCCCATGGTCCAGTCCCCAGGAAGGACATCATCAACC Sequencing with primer \#24 AAAGGGCCCATGGICCAGICCCCAGGAAGGACATCATCAACC

\author{
Point of mutation \\ $411 \mathrm{G}>\mathrm{C}$
}

Additional mutation $427 \mathrm{~T}>\mathrm{C}$

Figure 6. Verification of Passages 2 and 3 allantoic fluid inoculated with rAF- 411G $>$ T-GFP-4 and -7. (a) HA test of Passage 2 showed that rAF-411G>T-GFP-4 still produced no HA titre; whereas a HA titre of $2^{6}-2^{7}$ was observed for rAF-411G>T-GFP-7. (b) HA test of Passage 3 showed a HA titre of $2^{6}$. (c) Sequencing results of Passage 3 showed that the mutations $411 \mathrm{G}>\mathrm{C}$ and $427 \mathrm{~T}>\mathrm{C}$ were still observed. 


\section{DISCUSSION}

In this study, the attempt at reducing pathogenicity was to mutate the $\mathrm{V}$ protein, which serves as an interferon antagonist in hosts. Mutation of the $\mathrm{V}$ protein may not only reduce the pathogenicity of the virus, but it may also retain its oncolytic potential, since the $\mathrm{V}$ protein is not a surface protein and does not affect binding and infection of the virus. The $\mathrm{V}$ protein is encoded from the $P$ gene template when, during RNA editing, an extra $G$ nucleotide is inserted into a conserved editing site, causing a frameshift. In this study, a mutation of $\mathrm{G}$ into $\mathrm{T}$ at position 411 from the start of $P$ gene, $411 \mathrm{G}>\mathrm{T}$, was introduced. It was located a few nucleotides after the conserved editing site and will code for a premature stop codon on the $\mathrm{V}$ mRNA while leaving a silent mutation in the $\mathrm{P}$ protein (Table 3). The silent mutation allows the $P$ protein to be translated normally, allowing for uninterrupted transcription and replication of the virus. Several other single mutations further downstream from the conserved editing site also code for premature stop codons; this mutation was selected as the first mutation to be studied, and also since it was located closest to the conserved editing site, it would truncate the $\mathrm{V}$ protein the most. This mutation was introduced via a primer carrying the mutation as described above. Since the mutation is located close to the restriction site of PspOMI, the primer was designed in a way that includes the restriction site and hence can be used in direct PCR.

Table 3. Comparison of amino acid sequences of $\mathrm{P}$ and $\mathrm{V}$ proteins between wild type AF2240-I and $411 \mathrm{G}>\mathrm{T}$ mutation.

\begin{tabular}{|c|c|c|c|c|c|c|}
\hline \multirow[b]{2}{*}{$\begin{array}{l}\text { Wild type } \\
\text { AF2240-I }\end{array}$} & \multicolumn{3}{|c|}{$\begin{array}{c}\text { Sequence and amino acids coded } \\
\text { in } P \text { protein }\end{array}$} & \multicolumn{3}{|c|}{$\begin{array}{l}\text { Sequence and amino acids coded in } \\
\qquad \text { V protein }\end{array}$} \\
\hline & $\begin{array}{l}\text { GGC CCA UGG } \\
\text { UCG AGU }\end{array}$ & $\longrightarrow$ & GPWSS & $\begin{array}{l}\text { GGG CCC AUG } \\
\text { GUC } \underline{G A G}\end{array}$ & $\longrightarrow$ & GPMVE \\
\hline $\begin{array}{l}411 G>T \\
\text { mutation }\end{array}$ & $\begin{array}{l}\text { GGC CCA UGG } \\
\text { UCE AGU }\end{array}$ & $\longrightarrow$ & GPWSS & $\begin{array}{l}\text { GGG CCC AUG } \\
\text { GUC } \underline{\mathrm{U} A G}\end{array}$ & $\rightarrow$ & GPMV* \\
\hline
\end{tabular}

The mutation does not affect the amino acid sequence in $\mathrm{P}$ protein but produced a premature stop codon in the $\mathrm{V}$ protein.

After transfection, the supernatant was inoculated into embryonated chicken eggs for amplification of rescued virus. However, sequencing results of the RNA extracted from the rescued virions in the allantoic fluid showed that the desired mutation of $\mathrm{G}$ into $\mathrm{T}$ had been mutated into a $\mathrm{C}$ residue instead. This resulted in the change of glutamic acid to glutamine in the $\mathrm{V}$ protein instead of a premature stop codon as planned. In addition, an additional mutation further downstream, and also from $\mathrm{T}$ to $\mathrm{C}$, changed the tyrosine of $\mathrm{P}$ protein to histidine and isoleucine of the $\mathrm{V}$ protein to threonine. It was deducted that these mutations are caused by the infidelity of RNA genome replication due to the absence or low efficiency of proofreading and mismatch repair activities of RNA replicase and transcriptase, especially so with the case of single-stranded RNA genomes (Duarte et al., 1994; Domingo \& Holland, 1997).
The relaxed polymerase fidelity in RNA virus is essential for the virus to adapt to changing environment and to survive host immune system, upon which natural forces select changes in an adaptive evolution process (Duarte et al., 1994; Miller et al., 2009; Barr \& Fearns, 2010). It is very likely that the specific mutation introduced during site-directed mutagenesis could be changed to other nucleotides which are not intended. This is supported by Sanjuán (2010) who concluded that some mutations that were expected to be beneficial when focusing on a given function may compromise other viral functions such as replication, posing as a strong fitness cost, and such mutations will usually be selected against.

To overcome this problem, it would be wise to introduce multiple mutations in the $P$ gene to produce a $\mathrm{V}$ mRNA that would code for multiple premature stop codon. Ultimately, if the first 
premature stop codon was mutated, the following premature stop codon will warrant the truncation of the $\mathrm{V}$ protein and prevent it from being fullyexpressed. Currently, there are limited information regarding the $\mathrm{V}$ protein and detailed mechanisms on how it antagonises the interferon system. NDV with truncated $\mathrm{V}$ proteins of different lengths would allow us to understand the specific region on the $\mathrm{V}$ protein that is responsible for the antagonistic activity. Further passaging also showed that the mutations persisted, and the viruses still retained their infectious ability. Since we were interested to know how these mutations will affect the pathogenicity of the virus, pathogenicity testing was proceeded.

Mean death time (MDT) was chosen as the method of pathogenicity determination in this study. The use of SPF eggs in MDT assay is essential because NDV might not be able to kill the embryos due to the presence of high level of maternal antibodies in non-SPF eggs, causing an increase in mean death time and rendering the indication of pathotypes unreliable. From the results, it was observed that the pathogenicity of the mutated rAF-411G>T-GFP-7 has been reduced to the mesogenic level, with a mean death time of $73.6 \mathrm{~h}$. Although the desired mutation of $411 \mathrm{G}>\mathrm{T}$ was not obtained after virus recovery, we can deduce that the mutations $411 \mathrm{G}>\mathrm{C}$ and $427 \mathrm{~T}>\mathrm{C}$ produced by the viral RNA polymerase might be a survival mechanism which can be further explored. Nonetheless, the MDT results proved that the pathogenicity of the mutated NDV has been reduced to that of the mesogenic strain. Taken together, a recombinant NDV with reduced pathogenicity was successfully produced.

The mutated recombinant virus should be analysed for its anticancer property through in vitro and in vivo tests. To date, there is no study reported on the effect of $\mathrm{V}$ protein truncation on the oncolytic activities of the virus. If the mutated virus retains its oncolytic activities, further manipulation of the virus through reverse genetics can be carried out. The pathogenicity of the mutated recombinant virus could be further reduced to that of the lentogenic strain. This could be achieved by carried out mutation on other virulence factors on the viral genome. The resulting virus should again be tested for its anticancer properties.

\section{ACKNOWLEDGEMENTS}

This study was supported by the Newton Ungku Omar grant (MR/P012795/1), UPM grants (GPIBT/2013/9425600) and (GP/2018/9600700). Lee B. R. was supported by Graduate Research Fellowship (GRF), UPM.

\section{CONFLICT OF INTERESTS}

The authors have declared that no conflict of interest exists.

\section{REFERENCES}

Alexander, D. J. 1988. Newcastle Disease. Ed. Alexander, D. J. Boston: Kluwer Academic Publishers.

Barr, J. N., \& Fearns, R. 2010. How RNA viruses maintain their genome integrity. Journal of General Virology 91(6): 13731387.

Cheng, X., Wang, W., Xu, Q., Harper, J., Carroll, D., Galinski, M. Suzich, J., \& Jin, H. 2016. Genetic modification of oncolytic Newcastle disease virus for cancer therapy. Journal of Virology 90(11): 5343-5352.

Czeglédi, A., Ujvári, D., Somogyi, E., Wehmann, E., Werner, O., \& Lomniczi, B. 2006. Third genome size category of avian paramyxovirus serotype 1 (Newcastle disease virus) and evolutionary implications. Virus Research 120(1-2): 36-48.

de Leeuw, O. S., Koch, G., Hartog, L., Ravenshorst, N., \& Peeters, B. P. H. 2005. Virulence of Newcastle disease virus is determined by the cleavage site of the fusion protein and by both the stem region and globular head of the haemagglutinin-neuraminidase protein. Journal of General Virology 86(6): 1759-1769.

Deng, R., Mirza, A. M., Mahon, P. J., \& Iorio, R. M. 1997. Functional chimeric HN glycoproteins derived from Newcastle disease virus and human parainfluenza virus-3. Archives of Virology 13: 115-130.

Domingo, E., \& Holland, J. J. 1997. RNA virus mutations and fitness for survival. Annual Review of Microbiology 51: 151178 .

Duarte, E. A., Novella, I. S., Weaver, S. C., Domingo, E., WainHobson, S., Clarke, D. K., Moya, A., Elena, S. F., Torre, J. C., \& Holland, J. J. 1994. RNA virus quasispecies: significance for viral disease and epidemiology. Infectious Agents and Disease 3(4): 201-214.

Flanagan, A. D., Love, R., \& Tesar, W. 1955. Propagation of Newcastle disease virus in Ehrlich ascites cells in vitro and in vivo. Proceedings of the Society for Experimental Biology and Medicine. Society for Experimental Biology and Medicine (New York, N.Y.) $90(1):$ 82-86.

Galinski, M. S. 1991. Paramyxoviridae: transcription and replication. Advances in Virus Research 39: 129-162.

Huang, Z., Panda, A., Elankumaran, S., Govindarajan, D., Rockemann, D. D., \& Samal, S. K. 2004. The hemagglutinin-neuraminidase protein of Newcastle disease 
virus determines tropism and virulence. Journal of Virology 78(8): 4176-4184.

Kalyanasundram, J., Hamid, A., Yusoff, K., \& Chia, S. L. 2018. Newcastle disease virus strain AF2240 as an oncolytic virus: A review. Acta tropica, 183: 126-133.

Khattar, S. K., Yan, Y., Panda, A., Collins, P. L., \& Samal, S. K. 2009. A Y526Q mutation in the Newcastle disease virus $\mathrm{HN}$ protein reduces its functional activities and attenuates virus replication and pathogenicity. Journal of V irology 83(15): 7779-7782.

Krishnamurthy, Sateesh, \& Samal, S. K. 1998. Nucleotide sequences of the trailer, nucleocapsid protein gene and intergenic regions of Newcastle disease virus strain Beaudette $\mathrm{C}$ and completion of the entire genome sequence. Journal of General Virology 79(10): 2419- 2424.

Lai, M. C., \& Ibrahim, A. 1987. Velogenic viscerotropic Newcastle disease virus. In: Disease in Poultry: A New Food Pellet Vaccine. Ed. Copland, J. W., 5th ed., pp. 33-34. Canberra: ACIAR.

Lam, H. Y., Yeap, S. K., Rasoli, M., Omar, A. R., Yusoff, K., Suraini, A. A., \& Alitheen, N. B. 2011. Safety and clinical usage of Newcastle disease virus in cancer therapy. Journal of Biomedicine and Biotechnology, 2011.

Lamb, R. A., \& Kolakofsky, D. 1996. Paramyxoviridae : the viruses and their replication. In: Fields Virology. Ed. Fields, B. N., Knipe, D. M. \& Howley, P. M., 3rd ed., pp. 1177-1203. Philadelphia: Lippincott-Raven.

Lancaster, J. E. 1976. A History of Newcastle Disease with Comments on its Economic Effects. World's Poultry Science Journal 32(02): 167-175.

Lee, T. C., Yusoff, K., Nathan, S., \& Tan, W. S. 2006. Detection of virulent Newcastle disease virus using a phage-capturing dot blot assay. Journal of Virological Methods 136(1-2): 224- 229.

Mebatsion, T., Verstegen, S., De Vaan, L. T. C., Römer-Oberdörfer, A., \& Schrier, C. C. 2001. A recombinant Newcastle disease virus with low-level $\mathrm{V}$ protein expression is immunogenic and lacks pathogenicity for chicken embryos. Journal of Virology 75(1): 420-428.

Miller, Patti J., Kim, L. M., Ip, H. S., \& Afonso, C. L. 2009. Evolutionary dynamics of Newcastle disease virus. Virology 391(1): 64-72

Morodomi, Y., Inoue, M., Hasegawa, M., Okamoto, T., Maehara, M., \& Yonemitsu, Y. 2013. Sendai virus-based oncolytic gene therapy. In: Novel Gene Therapy Approaches. Ed. Wei, M. \& Good, D. IntechOpen.

Morrison, T. G. 2003. Structure and function of a paramyxovirus fusion protein. Biochimica et Biophysica Acta 1614: 73-84.

Murulitharan, K., Yusoff, K., Omar, A. R., \& Molouki, A. 2013. Characterization of Malaysian velogenic NDV strain AF2240-I genomic sequence: a comparative study. Virus Genes 46(3): 431-40.

New England Biolabs. 2019. Dam-Dcm and CpG methylation. Retrieved from https://www.neb.com/tools-andresources/selection-charts/dam-dcm-and-cpg-methylation

Peeters, B. P., de Leeuw, O. S., Koch, G., \& Gielkens, A. L. J. 1999. Rescue of Newcastle disease virus from cloned cDNA: evidence that cleavability of the fusion protein is a major determinant for virulence. Journal of Virology 73(6): 50015009.

Qiu, X., Fu, Q., Meng, C., Yu, S., Zhan, Y., Dong, L., Song, C., Sun, Y., Tan, L., Hu, S., Wang, X., Liu, X., Peng, D., Liu, X., \& Ding, C. 2016. Newcastle disease virus v protein targets phosphorylated STAT1 to Block IFN-I Signaling. PLOS ONE 11(2): 1-23.

Reichard, K. W., Lorence, R. M., Cascino, C. J., Peeples, M. E., Walter, R. J., Fernando, M. B., Reyes, H. M., \& Greager, J. A. 1992. Newcastle disease virus selectively kills human tumor cells. Journal of Surgical Research 52(5): 448-453.
Rout, S. N., \& Samal, S. K. 2008. The large polymerase protein is associated with the virulence of Newcastle disease virus. Journal of Virology 82(16): 7828-7836.

Sanjuán, R. 2010. Mutational fitness effects in RNA and singlestranded DNA viruses: common patterns revealed by sitedirected mutagenesis studies. Philosophical Transactions of the Royal Society B: Biological Sciences 365(1548): 1975-1982.

Schirrmacher, Volker. 2016. Fifty years of clinical application of Newcastle disease virus: time to celebrate! Biomedicines 4(3): 16.

Sergel, R., McGinnes, L. W., \& Morrison, T. G. 1993. The fusion promotion activity of the NDV HN protein does not correlate with neuraminidase activity. Virology 196: 831-834.

Sergel, T. A., McGinnes, L. W., \& Morrison, T. G. 2000. A single amino acid change in the Newcastle disease virus fusion protein alters the requirement for $\mathrm{HN}$ protein in fusion. Journal of Virology 74(11): 5101-5107.

Sergel, T., McGinnes, L. W., Peeples, M. E., \& Morrison, T. G. 1993. The attachment function of the Newcastle disease virus hemagglutinin-neuraminidase protein can be separated from fusion promotion by mutation. Virology 193(2): 717 726.

Song, H., Zhong, L. P., He, J., Huang, Y., \& Zhao, Y. X. 2019. Application of Newcastle disease virus in the treatment of colorectal cancer. World Journal of Clinical Cases 7(16): 2143 2154.

Steward, M., Vipond, I. B., Millar, N. S., \& Emmerson, P. T. 1993. RNA editing in Newcastle disease virus. The Journal of General Virology 74: 2539-2547.

Yan, Y. \& Samal, S. K. 2008. Role of intergenic sequences in Newcastle disease virus RNA transcription and pathogenesis. Journal of Virology 82(3): 1323-1331.

Yan, C., Liu, H., Jia, Y., Prince-Theodore, D-W., Yang, M., Adam, F. E. A., Ren, J., Cao, X., Wang, X., Xiao, S., Zhang, S., \& Yang, Z. 2020. Screening and mechanistic study of key sites of the hemagglutinin-neuraminidase protein related to the virulence of Newcastle disease virus. Poultry Science 99(7): 3374-3384.

Yu, X., Cheng, J., Xue, J., Jin, J., Song, Y., Zhao, J. \& Zhang, G. 2017a. Roles of the polymerase-associated protein genes in Newcastle disease virus virulence. Frontiers in Microbiology 8: 161.

Yu, X., Cheng, J., He, Z., Li, C., Song, Y., Xue, J., Yang, H., Zhang, R. \& Zhang, G. 2017b. The glutamic residue at position 402 in the C-terminus of Newcastle disease virus nucleoprotein is critical for the virus. Scientific Reports 7: 17471.

Yusoff, K., Millar, N. S., Chambers, P., \& Emmerson, P. T. 1987. Nucleotide sequence analysis of the L gene of Newcastle disease virus: homologies with Sendai and vesicular stomatitis viruses. Nucleic Acids Research 15(10): 3961-3976.

Yusoff, K, \& Tan, W. S. 2001. Newcastle disease virus: macromolecules and opportunities. Avian Pathology 30(5): 439-455.

Zamarin, D., Martínez-Sobrido, L., Kelly, K., Mansour, M., Sheng, G., Vigil, A., García-Sastre, A., Palese, P., \& Fong, Y. 2009. Enhancement of oncolytic properties of recombinant Newcastle disease virus through antagonism of cellular innate immune responses. Molecular Therapy 17(4): 697-706. 